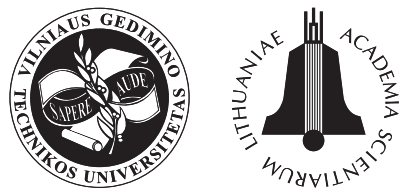

TRANSPORT

2010

25(3): 293-299

\title{
PLANNING ORGANIZATION AND PRODUCTIVITY SIMULATION TOOL FOR MARITIME CONTAINER TERMINALS
}

\author{
Bojan Beškovnik ${ }^{1}$, Elen Twrdy ${ }^{2}$ \\ ${ }^{1}$ Intereuropa, Global logistics service, Ltd. Co., Vojkovo nabrezje 32, Koper, Slovenia \\ ${ }^{2}$ University of Ljubljana, Faculty of Maritime Studies and Transport, \\ Pot pomorscakov 4, Portoroz, Slovenia \\ E-mails: ${ }^{1}$ bojan.beskovnik@intereuropa.si; ${ }^{2}$ elen.twrdy@fpp.uni-lj.si
}

Received 12 December 2009; accepted 19 July 2010

\begin{abstract}
The article describes a proposed planning organization and productivity simulation tool, with a special emphasis on orientations to the optimization of operations in a maritime container terminal. With the application of an adequate model frame for traffic and technical-technologic forecasting, infrastructure and manpower planning and productivity simulation are possible to measure and increase the productivity in the whole subsystem of the maritime container terminal. The emphasis is mainly put on setting up planning organization in order to collect important information and consequently to raise productivity. This is the main task and goal of terminal management that must develop elements and strategies for optimal operational and financial production. An adequate planning structure must use simplified but efficient simulation tools enabling owners and management to take a vast number of adequate financial and operational decisions. Considering all important and very dynamic facts in container and shipping industry, the proposed simulation tool gives a helpful instrument for checking productivity and its time variation and monitoring a competitive position of a certain maritime terminal with the terminals from the same group. Therefore, the management of every maritime container terminal must establish an appropriate internal planning system as a mechanism for strategic decision support relating basically to the assessment of the best development and optimization solutions for the infrastructure and suprastructure of the entire system.
\end{abstract}

Keywords: maritime container terminals, planning organization, productivity, simulation tool, infrastructure optimization, information flow.

\section{Introduction}

Generally, terminals are the systems performing different operations such as a start or end point for goods in transit. On a macro level, a maritime container terminal can be defined as a facility enabling the transfer of intermodal units promptly, safely and correctly between the different modes of transport. A container terminal is hence the basic intermodal node in the logistics network, and for this reason, all operations involved in the flow of goods and containers have to be harmonized and optimised. In all systems, the main focus is mainly on the seaside where an operation on the vessel represents the primary service of the system. Consequently, all maritime terminals must be properly equipped and organized in order to provide operational and financial optimum. Certainly, there are big differences between terminals in sense of infrastructure, technical equipment and handling capacities deeply analysed by Steenken et al. (2004).
Nowadays, all maritime terminals are under pressure to reduce costs and perform time savings enabling all players in the logistics chain a lean supply chain management, including inland dry ports (Jaržemskis and Vasilis Vasiliauskas 2007). The ability of port companies to provide tailor-made services has become fundamental to the overall effectiveness of the port within the supply chain. Therefore, they are forced to reduce unproductive time and to offer effective processes in order to meet increasing competition among terminals. This situation was carefully analysed by Liu et al. (2009). Paixão and Marlow (2003) suggest that ports could contribute to more cost-effective logistics with focusing their efforts on the specific areas of their operational activity (particularly on $20 \%$ of their activity where they gain $80 \%$ of their revenues) and on reducing storage costs even up to $30 \%$. Container terminals working as specialized systems are therefore a step forward compared to the systems work- 
ing in large port systems. They can constantly search for system optimization concerning not only productivity but also space efficiency. Performance measured with productivity and space efficiency is determined by different dynamic elements. Watanabe (1991) proposed several performance measures used in container terminals. The main challenge of increasing productivity is a lack of balance between the capacity of different elements and disco-ordination in consecutive operations. An increase in the efficiency of a container terminal is mandatory to ensure sufficiently short lay time for container vessels in the port and to achieve a further reduction in terminal operating costs.

Therefore, the appropriate management of the entire system is a very complex process and requires a huge number of different time limited decisions. Different simulation tool systems have been developed for decision support; however, they cannot replace simultaneous operational and financial decisions.

From an economic point of view, the system has an objective of maximizing profit. In this respect, efficient container handling at terminals is important for reducing transportation costs and secure time savings. The owners or management of a maritime container terminal must develop an adequate tool for collecting and assessing performance measurement and increase productivity without high financial investments. According to researches, this is an important but difficult task as more than $70 \%$ of attempts to implement performance measurement systems fail (Beresford et al. 2004).

Based on the above displayed information, the idea is to develop universal planning organization that might be applied in every maritime container terminal and at the same time, used as a productivity simulation tool with a special emphasis on system productivity. The main focus is to define system optimization structure in order to implement an adequate model for collecting information and forecasting activities. With efficient organization planning and an appropriate decision structure, the balanced development of the entire system and long-term planning activities should be secured. Consequently, the article presents an in-deep overview of productivity optimization and gives proposals to the operators or owners of container terminals and to all external business subjects.

\section{Efficient Planning Organization}

Container terminals are becoming very complex systems. Due to globalization trends and the dynamic nature of the environment, a large number of timely decisions have to be continuously reviewed and adapted. The management of the container terminal is under constant pressure to find internal optimization in every-day working processes. Consequently, different working parameters of the terminal must be constantly measured. This is an important but difficult task because different productivity parameters change continuously. System competitiveness therefore more than ever depends on the quality of services provided by the operators that are required to improve flexibility in management and cost reduction through an adequate set of facilities and an efficient organization of container manipulations (Yun and Choi 1999; Kim et al. 2000).

The phase of measurement and optimization is only one of the important processes in planning decisions. Namely, the infrastructure and suprastructure of the terminal must first be defined and confirmed by the management of the terminal, which is normally based on yearly container traffic forecast (by sea and by land). The forecasting process is therefore an important phase of planning and can be classified as the first phase of the planning process on the container terminal.

Another very important process should be considered in establishing a planning model frame. The process of simulations has an important contribution as it includes calculations of terminal productivity parameters. Simulation makes possible to set up the infrastructure and suprastructure of the terminal and to define the required working processes. Moreover, needed manpower and working costs can be simulated and finally presented to management.

\subsection{The Structure of Planning Organization}

The idea is to establish universal planning organization which should be applied in every maritime container terminal. Consequently, such a model frame should be organized in the maritime container terminal through planning service. The system matrix is easily modelled and described through different indispensable modules and interaction between them. Gambardella et al. (1998) worked out a modular system approach in order to describe important decision support models. With reference to our previous research, we defined the architecture of a planning system which was additionally upgraded and worked out by new researches (Twrdy and Beškovnik 2008). Consequently, we propose a six module planning model frame, with a special emphasis on planning a service organization and simulation module (Fig. 1). The process of planning organization consists of:

- traffic development forecast module,

- technical-technologic forecasting module,

- productivity simulation module,

- infrastructure and suprastructure planning module,

- manpower planning module,

- optimization module.

The first module performs the phases of forecasting economy development and the development of containerisation at local and wider regional levels. All these aspects must consider a potential traffic volume of containers through the maritime terminal. The second module analyses new technical-technologic cognitions in the fields of transport, which can be adopted in the existent maritime container terminal. Both modules include forecasting processes, and therefore probability methods are important factors to consider.

The module of simulation is also usable in case of an existent terminal and has to be used more frequently in small maritime container terminals. A productivity 


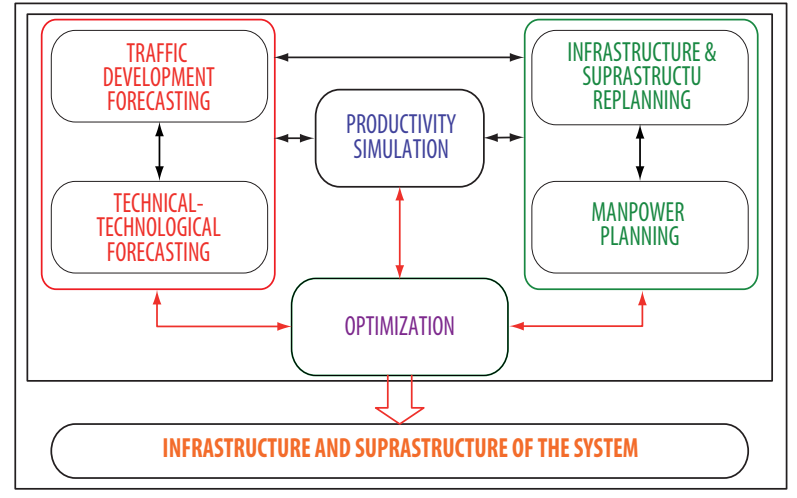

Fig. 1. Six phase planning model frame for container terminals (Source: the model worked out by authors)

simulation module must consist of real data and detailed research on infrastructure and suprastructure because a great number of various factors influence the operation of the terminal and may cause its malfunction, however, their influence may differ to a great extent (Baublys 2007). A huge number of methods and models can be used and simultaneously supported employing different IT tools. Different simulation approaches were made by some authors. Yun and Choi (1999) worked out a simulation model for operation analysis, meanwhile Hartmann (2004) analysed simulation and optimization scenarios for container terminal logistics.

The infrastructure and suprastructure planning module is indirectly connected with the previously described modules. It must consider forecasts and cognitions acquired by simulations enabling terminal planners to optimize the processes of the entire system and the structure per each subsystem. Manpower planning is an every-day process and has a strong impact on cost efficiency. It is important to define optimal employment policy and at the same time, to have manpower flexibility.

According to the planning model frame proposed in Fig. 1, the last optimization module must use cognitions of all five modules. An impact of each described modules has an important influence on optimization which is a wider process and is not focused on infrastructure optimization only. Therefore, different profiles of experts such as equipment-planners, engineers, economists, architects etc. must be involved. Different methods can be used for the optimization module, but with empiric calculations of system activities, particularly productivity and exploitation parameters can be defined.

\subsection{Principal Goals of Planning Structure}

The proposed planning organization consists of six equivalent modules. It is an important tool for the management of a maritime container terminal as it enables an adequate valuation of the development possibilities of the entire system and gives proposals how to raise productivity and define service quality. The main goal is to raise the efficiency and service quality as different researches proved that instead of lower costs, the users frequently searched for higher productivity, efficiency and quality. Research done by $\mathrm{Ng}$ (2006) also showed that users choosing between different Northern-European container ports were mostly influenced by efficiency and service quality rather than by lower costs.

The main optimization decision segments include:

- defining efficient activities of loading and discharging processes on all subsystems, in view of needed time and costs;

- defining optimal storage capacity, in view of needed time for operation and costs;

- searching for internal possibilities of upgrading system activity;

- defining service quality indicators to improve system quality;

- making strategies for the future development of the system.

The proposed model frame must be a base for activities planning the service of a maritime container terminal where special focus must be also on service quality. Parasuraman et al. (1985) have determined five most important elements defining service quality: reliability, responsibility, intangibility, empathy and assurance. All these elements are very important factors nowadays. In addition, different attributes can be added to each service quality element. This way balanced development of terminal activities, the constant development of the subsystems of the terminal, the application of adequate processes per each subsystem and consecutively higher productivity can be achieved. Achievements in all above mentioned factors leads to higher system efficiency and quality as well as reflects on good financial operations of a maritime container terminal (Bagdoniene 2008; Batarlienė and Jarašūnienė 2009; Baublys 2009; Gromule and Yatskiv 2007; Hess et al. 2007; Hess and Hess 2010; Jaržemskienè 2007; Liu et al. 2009; Tolli and Laving 2007; Vasilis Vasiliauskas and Barysienè 2008).

\section{Defining a Productivity Simulation Tool}

A productivity simulation module is an important element of planning organization. The main goal is to define and set up an appropriate simulation tool which can give some real data about system productivity. In addition, an important point is gaining information on with which container terminal a certain maritime container terminal can be compared and what operational data should be used for a dynamic comparison.

The proposed simulation tool (Fig. 2) is an extended and further developed model based on the previously performed research (Beškovnik and Twrdy 2009). The object-oriented tool consists on empiric investigation into infrastructure and handling equipment. The basic working parameters used for terminal productivity measurement always contain already standard indicators such as yearly throughput, berth loading and unloading manipulations per crane or per hour, yard loading and unloading operations, berth and yard occupancy, the number of vehicles at the entrance in the terminal by truck or by rail, waiting time in the entrance, the number of waiting vessels on the anchorage etc. All these param- 


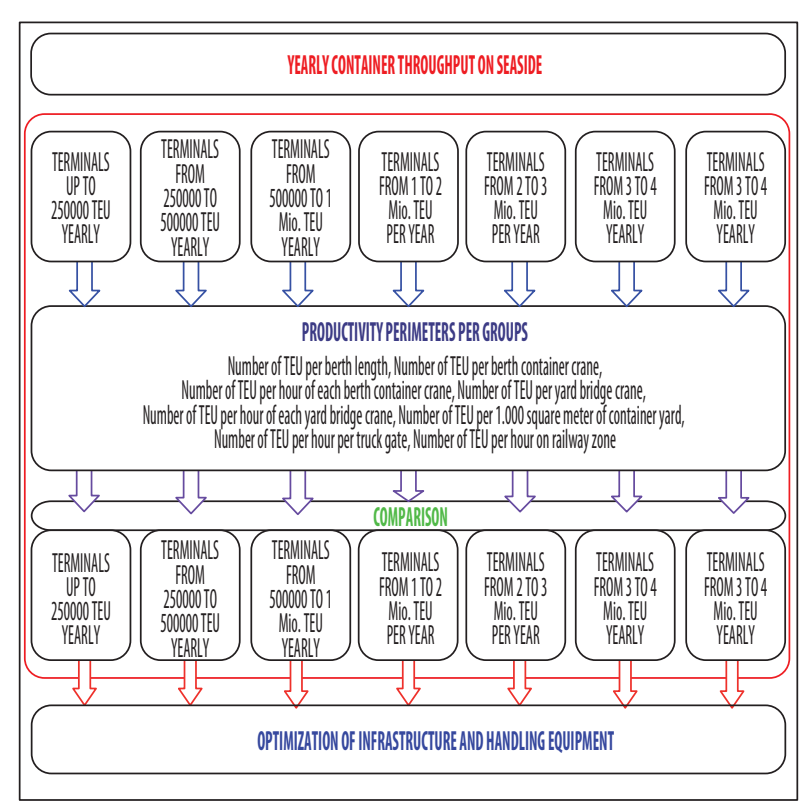

Fig. 2. Productivity simulation model for maritime container terminals (Source: the model worked out by authors)

eters are dynamic variables and change continuously. Thus, it is of high importance to check and adjust them frequently and the main goals of the proposed simulation tool are:

- evaluation of productivity on the berth in direct connection with total yearly throughput;

- evaluation of container terminal equipment availability and exploitation;

- evaluation of yard productivity in connection with yearly throughput;

- evaluation of gate productivity in connection with the yearly throughput of containers transported by trucks;

- evaluation of railway zone productivity in connection with the yearly throughput of containers transported by rail;

- evaluation of productivity and a possibility of having a general overview of the applicable results.

\subsection{Defining Groups of Maritime Container Terminals}

The described productivity simulation tool was further developed according to the obtained results from the research performed on over forty different container terminals from different regions where all terminals formed four groups (Beškovnik and Twrdy 2009):

- Group 1 - terminals with the throughput up to 500000 TEU;

- Group 2 - terminals with the throughput from 500000 to 1 mio. TEU;

- Group 3 - terminals with the throughput from 1 to 3 mio. TEU;

- Group 4 - terminals with the throughput over 3 mio. TEU.

The average annual throughput of all ten ports from the first group was 302222 TEU with an average of
59185 TEU of movements per berth crane. The average performance of a single crane was 8 TEU per hour and the average yard utilization was 1402 TEU per $1000 \mathrm{~m}^{2}$. The average annual throughput of the 2 nd group was 702298 TEU. The average data for all performance perimeters was significantly higher in comparison with that obtained from the 1st group. The average performance on an annual basis per single berth crane was 99762 TEU; meanwhile, the average performance of a single crane in the group was 14 TEU per hour. The average yard utilization was nearly three times higher in comparison with data obtained from the 1st group as all terminals from the 2nd group reached 3182 TEU per $1000 \mathrm{~m}^{2}$ on average.

The average annual throughput of the 3 rd group was 1946028 TEU, with an average of 116843 TEU of movements per berth crane. The average performance of a single crane was 16 TEU per hour and the average yard utilization was 3870 TEU per $1000 \mathrm{~m}^{2}$. Production perimeters for the last group of terminals were unequivocally on a very high level. Performance on the seaside was very close to 150000 TEU per berth crane. Furthermore, performance per crane hour was over 20 movements and yard utilization was on average over 5000 TEU per $1000 \mathrm{~m}^{2}$.

The previously structured model demonstrated that there was too large gap between different groups of terminals. Consequently, they should be additionally divided in more groups because there are a lot of infrastructural and operational differences between them. Based on this, the proposed model consists of seven groups of maritime container terminals classified in one of the groups according to their yearly throughput measured with manipulations on the seaside, which result in the number of manipulation for loading and unloading containers from and on container vessels.

The 1st group contains container terminals with the yearly throughput of up to 250000 TEU (twenty equivalent unit - equal to one $20^{\prime}$ container) and represents small maritime container terminals with only a local or regional transport function. The 2 nd and 3 rd groups include container terminals with yearly throughput between 250000 and 500000 TEU and terminals between 500000 to 1 million TEU of yearly throughput. The terminals from these two groups are classified as medium size maritime container terminals with an important regional traffic role. The 4 th group involves container terminals with yearly throughput between 1 and 2 million TEU, meanwhile the 5th group contains container terminals with yearly throughput between 2 and 3 million TEU. These systems are acting on the market as important regional and global shifting points. Maritime container terminals with yearly throughput between 3 and 4 million TEU are grouped in the 6th group. The last group covers terminals with the throughput of over 4 million TEU and this is the group with only a few biggest container terminals in the world. Their yearly throughput clearly shows they are playing an important hub role on the main trans-national routes around the world. 
The proposed model deals with seven groups and can analyse container terminals even in a more detailed way. Breaking the above mentioned groups only on half a million TEU of yearly throughput would create a higher number of groups with a smaller gap in yearly throughput between them and consequently, a more detailed simulation model.

\subsection{Defining Productivity Perimeters}

Different productivity indicators can be used for simulation and describing system efficiency. Productivity indicators clearly indicate the productivity of each subsystem, the way of how adopted infrastructure and handling equipment is exploited and what the performance of skilled manpower is. The developed and described simulation tool uses eight most important productivity perimeters in order to cover the main infrastructural exploitation.

Thus, the berth yard and delivery zone production of a maritime container terminal is processed with the below presented production perimeters:

- number of TEU per berth length;

- number of TEU per berth container crane;

- number of TEU per hour of each berth container crane;

- number of TEU per yard bridge crane;

- number of TEU per hour of each yard bridge crane;

- number of TEU per $1000 \mathrm{~m}^{2}$ of the container yard;

- number of TEU per hour per truck gate;

- number of TEU per hour on the railway zone.

\subsection{Analysing Data for Optimization}

A simulation tool therefore consists of seven groups analysed applying eight productivity perimeters. A comparison of production data between these groups can give a general overview of productivity that can be achieved by a certain terminal. Moreover, simulation can show optimization possibilities and how a comparison can be done between different maritime container terminals.

It can be anticipated that smaller maritime container terminals achieve lower production on berth and yard subsystems. This is directly related to the sophisticated handling equipment used by bigger terminals enabling them to perform a higher density of container storage on the yard and higher production per berth container crane.

The terminals from the first two groups usually utilize shorter berth length and also berth cranes with theoretical lower handling capability. Such infrastructure and suprastructure can accommodate smaller and middle-sized container vessels. These terminals also need a wider storage platform as they mainly use manipulators and forklifts for container handling and in most cases are in function of regional entering and outgoing points. The terminals from the 2 nd and 3 rd groups use more sophisticated technology, and therefore their cranes can handle a greater number of containers per hour. According to the research study, the previously performed differences between groups are enormous.

Subsequently, it is important to rank a terminal in a certain group even it is placed in a completely different region on the other side of the globe. The comparison must be done with an average value of the ranking group. In case the productivity indicators of the analysed maritime container terminal are lower than the average value, it can be confirmed that the analysed system is not achieving optimal performance. Moreover, it can be defined which parameters are critical and which are working on the acceptable levels. In case all indicators show higher performance results, it can be confirmed that the analysed system achieves acceptable levels and additional optimization is not necessary.

\section{Setting up an Optimization Structure}

According to the described organization planning and the main goal to propose an optimization approach and structure to be adopted on the maritime container terminal, it is also necessary to define an efficient structure to further process the collected data. An important point is setting up an adequate structure of collecting strategic information. Moreover, the data received from simulations and forecasting data should be internally processed to define system optimization. The proposed structure (Fig. 3) uses the pyramidal model shape in order to describe the hierarchy of decision-making and the level of responsibility for the adoption of cognitions obtained with simulations and forecasts.

It is important to collect information on the systems and subjects of the surroundings because national and international economies along with their policy greatly influence a technical profile and physical flow of containers through the system (Franke et al. 2001). All 2PL, 3PL, $4 \mathrm{PL}$ and ocean carriers have a lot of applicable information because they represent the interests of the cargo and can achieve maximal benefit only with the optimal activities of the entire system. This communication is performed on the bottom-up mode shown in Fig. 3.

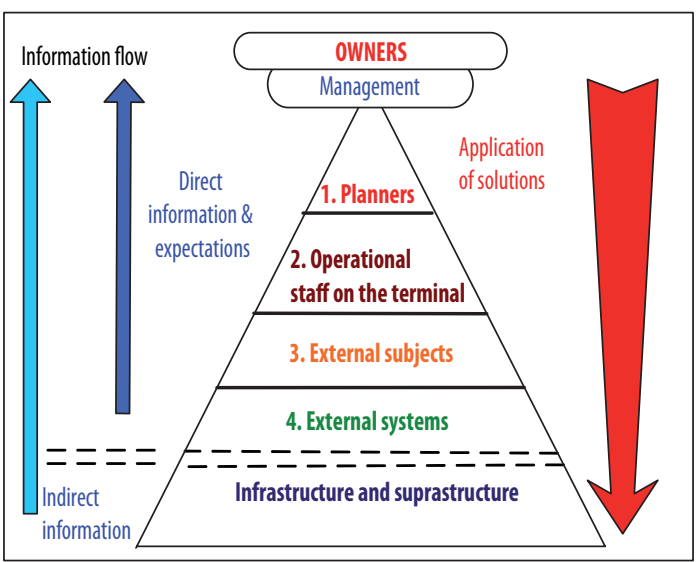

Fig. 3. Information flow and importance of decisions for terminal activity simulations (Source: the model worked out by authors) 
According to our model, operational staff also plays a crucial role in collecting information. Their information help with better understanding and analysing data obtained from simulations since the cognitions of the labour force are based on actually registered workinformation during direct contacts with manipulation means and transport systems. Accordingly, lower or higher productivity parameters can be better understood (Beškovnik 2008).

\subsection{Important Role of Planners}

The proposed information collecting model (Fig. 3) puts planners on a higher level. During their work, they must take into consideration important cognitions and working factors of the entire system. Apart from their new cognitions, based mainly on forecasts, simulations and planning activities, it is possible to form optimal operational and structural solutions for the entire system. When using such structure and organisation, it is possible to qualitatively collect key data for good and oriented decision-making.

Planners must be informed about difficulties and bottlenecks in the terminal because this is the way they can work-out adequate solutions. Some optimization proposals are directly connected with investments, and therefore the order of decision precedence must be congruent with the needs to increase productivity and with higher financial results. Planners must be an active part of information flows in order to be able to set up a decision model of how to manage container flows, how to increase the productivity of the present system and how to achieve the desired level of optimization.

It is important that the structure of planners is diversified by different experts. Due to a deeper understanding of optimization, in respect of infrastructural optimization and financial optimization, engineers, architects and economists should actively participate in optimization processes. All roles are significant in order to assure harmonised decisions.

Based on the worked out structure described in Fig. 3, we propose a bottom-up model to collect all relevant information and expectations from all significant players in the logistics chain and put forward an up-bottom model for implementing optimal operational solutions.

\subsection{Determining Optimal Elements and Dimensions}

Planners must locate the bottleneck elements of terminal capacities and their impacts on other subsystems and processes. It is very important to analyze the impacts of the higher productivity of one subsystem on other subsystems in order to avoid the exact opposite effects on all other subsystems. Choi (2003) analysed and confirmed the connectivity of these impacts on the case of Pusan port.

In practice, it is very difficult to determine the dimension and optimal capacity of a maritime container terminal because of irregular vessel arrivals and duration of unloading manipulations. The system should always have some reserve capacities at disposal in order to ac- cept and unload or load all containers at arrival or departure. Such reserve capacities of the system contribute to the lowest terminal efficiency and undoubtedly increase the fixed costs.

It must be also taken into consideration that a huge number of external factors have an influence on the productivity of a maritime container terminal where planners do not have influence:

- location and availability of the land for terminal expansion;

- land connections and the quality of these connections;

- the number of continental transport means and the quality of service;

- the number and characteristics of container terminals in the nearby locations;

- local, national and regional traffic policy;

- ownership and management structure in the port and port policy as a system.

All the above introduced characteristics have impacts on determining optimal elements and dimensions. Another important point is that the management of a maritime container terminal does not want long queuing rows at sea and land side because these facts can influence cargo owners and carriers to leave the terminal and move its services to the neighbouring ports (Bielli et al. 2006). At the same time, planners must consider that lower efficiency increases working costs which are not acceptable by the management and owners of the terminal. Consequently, it is a challenge to find an optimum solution between productivity and financial operations.

\section{Conclusions}

1. International ocean freight container transportation has grown drastically in the last decade. Maritime container terminals are becoming key factors in supply chains as economical crises put new pressure on lean activities. These systems are still under pressure to continuously upgrade their infrastructure and suprastructure. Consequently, they must provide more efficiency in container and financial operations. Moreover, the need to set up an adequate planning model for short and long-term decision-making processes appears.

2. The proposed and described six module planning organization should be an adequate answer to the increasing expectations of growing productivity. It enables the management of the terminal suitable valuation development possibilities and productivity increase. All six described modules are necessary and extremely important. Moreover, a high level of reconciliation between them must be present due to the fact that there is a constant interaction between information and material flows.

3. The main goal of every system must be to define and set up an appropriate simulation module able to give some real data about system productivity. Consequently, a productivity simulation module is an important element of system planning activities. 
For this reason, we proposed and developed a simplified productivity simulation tool that calculates and measures performance per subsystems. The model uses frequently and easily accessible performance measures. With a proper application, it is possible to locate unproductive elements and establish a proper strategy for necessary actions to increase productivity.

4. Through the proposed information collecting model, which also includes collecting information processes, the data obtained from simulations and forecasting should be additionally processed to define system optimization. Responsibility for adopting cognitions obtained with simulations and forecasts is expressed through a pyramidal shape. The structure includes all the components of crucial importance for making an efficient strategy for future business and development. Such structure creates a possibility of achieving the balanced development of the entire system and long-term planning activities satisfying the expectations and needs of owners and all external business subjects.

\section{References}

Bagdoniené, D. 2008. Optimization of loading facilities at the terminal, Transport 23(2): 95-97. doi:10.3846/1648-4142.2008.23.95-97

Batarlienè, N.; Jarašūnienè, A. 2009. Research on advanced technologies and their efficiency in the process of interactions between different transport modes in the terminal, Transport 24(2): 129-134. doi:10.3846/1648-4142.2009.24.129-134

Baublys, A. 2007. Probability models for assessing transport terminal operation, Transport 22(1): 3-8.

Baublys, A. 2009. Principles for modelling technological process in transport terminal, Transport 24(1): 5-13. doi:10.3846/1648-4142.2009.24.5-13

Beresford, A. K. C.; Gardner, B. M.; Pettit, S. J.; Naniopoulos, A.; Wooldridge, C. F. 2004. The UNCTAD and WORKPORT models of port development: evolution or revolution, Maritime Policy and Management 31(2): 93-107. doi:10.1080/0308883042000205061

Beškovnik, B. 2008. Measuring and increasing the productivity model on maritime container terminals, Pomorstvo - Journal of Maritime Studies 22(2): 171-183.

Beškovnik, B.; Twrdy, E. 2009. Productivity simulation model for optimization of maritime container terminals, Transport Problems - Problemy Transportu 4(3): 113-122.

Bielli, H.; Boulmakoul, A.; Rida, M. 2006. Objected oriented model for container terminal distributed simulation, $E \mathbf{U}$ ropean Journal of Operational Research 175(3): 1731-1751. doi:10.1016/j.ejor.2005.02.037

Choi, Y. S. 2003. Analysis of combined productivity of equipments in container terminal, Maritime Review 3(1): 57-80.

Franke, P.; Alicke, K.; Arnold, D. 2001. Modelling and Optimization of the Intermodal Terminal. IHL, Universitat Karlsruhe.

Gambardella, L. M.; Rizzoli, A. E.; Zaffalon, M. 1998. Simulation and Planning of an Intermodal Container Terminal, Simulation 71(2): 107-116. doi:10.1177/003754979807100205

Gromule, V.; Yatskiv, I. 2007. Coach terminal as important element of transport infrastructure, Transport 22(3): 200-206.
Hartmann, S. 2004. Generating scenarios for simulation and optimization of container terminal logistics, OR Spectrum 26(2): 171-192. doi:10.1007/s00291-003-0150-6

Hess, S.; Hess, M. 2010. Predictable uncertainty about terminal operations in the sea, Transport 25(2): 148-154. doi:10.3846/transport.2010.18

Hess, M.; Kos, S.; Hess, S. 2007. Queueing system in optimization function of port's bulk unloading terminal, $P R O$ MET - Traffic \& Transportation 19(2): 61-70.

Jaržemskiene, I. 2007. The evolution of intermodal transport research and its development issues, Transport 22(4): 296306.

Jaržemskis, A.; Vasilis Vasiliauskas, A. 2007. Research on dry port concept as intermodal node, Transport 22(3): 207-213.

Kim, K. H; Park, Y. M.; Ryu, K.-R. 2000. Deriving decision rules to locate export containers in container yards, European Journal of Operational Research 124(1): 89-101. doi:10.1016/S0377-2217(99)00116-2

Liu, W.; Xu, H.; Zhao, X. 2009. Agile service oriented shipping companies in the container terminal, Transport 24(2): 143-153. doi:10.3846/1648-4142.2009.24.143-153

Ng, K.-Y. 2006. Assessing the attractiveness of the ports in the North European container transhipment market, Maritime Economics and Logistics 8(3): 234-250. doi:10.1057/palgrave.mel.9100158

Paixão, A. C.; Marlow, P. B. 2003. Fourth generation ports a question on an agility?, International Journal of Physical Distribution and Logistics Management 33(4): 335-376. doi:10.1108/09600030310478810

Parasuraman, A; Zeithaml, V. A.; Berry, L. L. 1985. A conceptual model of service quality and its implications for future research, Journal of Marketing 49(4): 41-50. doi: $10.2307 / 1251430$

Steenken, D.; Voss, S.; Stahelbock, R. 2004. Container terminal operation and operations research - a classification and literature review, OR Spectrum 26(1): 3-49. doi:10.1007/s00291-003-0157-Z

Tolli, A.; Laving, J. 2007. Container transport direct call - logistic solution to container transport via Estonia, Transport 22(4): Ia-If.

Twrdy, E., Beškovnik, B. 2008. Planning and decision-making to increase productivity on a maritime container terminal, PROMET - Traffic \& Transportation 20(5): 335-341.

Vasilis Vasiliauskas, A.; Barysienė, J. 2008. An economic evaluation model of the logistic system based on container transportation, Transport 23(4): 311-315. doi:10.3846/1648-4142.2008.23.311-315

Watanabe, I. 1991. Characteristics and analysis method of efficiencies of container terminal - an approach to the optimal loading/unloading method, Container Age 3: 36-47.

Yun, W. Y.; Choi, Y. S. 1999. A simulation model for container terminal operation analysis using an object oriented approach, International Journal of Production Economics 59(1-3): 221-230. doi:10.1016/S0925-5273(98)00213-8 